Author Preprint: Hegarty, P. \& Buechel, C. (2006). Androcentric Reporting of Gender Differences in APA Journals: 1965-2004. Review of General Psychology, 10, 377-389.

\begin{abstract}
Androcentric thinking assumes maleness to be normative, and attributes gender differences to females. A content analysis of articles reporting gender differences published between 1965 and 2004 in four APA journals examined androcentric pronouns, explanations, and tables and graphs. Few articles used generic masculine pronouns to refer to both women and men. However, explanations of gender differences within articles that mentioned such differences in their abstracts and titles referenced attributes of women significantly more often than attributes of men. Most tables and graphs depicting gender differences positioned males' data before females' data, except when gender differences among parents were concerned. Psychologists have ceased to use male-centered pronouns, but female and male psychologists continue to report, explain, and depict gender differences in androcentric ways.
\end{abstract}

In her feminist classic, The Lenses of Gender, Sandra Bem (1993) described biological essentialism, gender polarization, and androcentrism as three cultural 'lenses' which distort both laypeople's, and scientists', perceptions of gender. Within and beyond psychology there has been repeated concern that such lenses impact the ways that psychological differences between females and males are reported and interpreted. Debates have focused on gender polarization; the exaggeration of gender differences (Baumeister, 1988; Favreau, 1997; Hare-Mustin \& Marecek, 1990; Hyde, 2005; Kitzinger, 1994; McHugh, Koeske, \& Frieze, 1986; Mednick, 1989), and on biological essentialism; the premature attribution of gender differences to immutable biological factors (e.g., Brescoll \& LaFrance, 2004; Mahalingam, 2003; Martin \& Parker, 1995; McHugh, Koeske, \& Frieze, 1986). The current article aims to call attention to the third lens of androcentrism.

Following Bem (1993) we define androcentrism as the implicit conflation of maleness with humanity and the consequent attribution of gender differences to females, often to women's disadvantage. Below, we review psychological evidence on androcentric biases to motivate the hypothesis that psychological research also constructs gender differences through this cultural lens. Previous research on androcentrism has focused on verbal measures, but we argue that androcentrism is also evidenced by visuospatial representations of group differences. We report a content analysis examining verbal and visuospatial representations of gender differences in forty years of psychological research, and use our findings to reframe debates about the way that we psychologists report gender differences, and the influence of cultural values on scientific thinking within our discipline.

Psychological Studies of Androcentric Thinking

The first component of androcentric thinking is the conflation of males with the norm (Bem, 1993; Silveira, 1980). Psychological evidence of such conflation abounds. Men are taken as the default for several social categories (Stroessner, 1996; Zárate \& Smith, 1990). Judgements about 'men' and 'people' are more similar than judgments 
about 'women' and 'people' in regard to stereotypes of national groups (Eagly \& Kite, 1986), mental health standards (Broverman et al., 1970), and attitudes toward sexual minorities (Black \& Stevenson, 1984). When prompted to think of 'famous people' people call men to mind more often than women, and men particularly show this bias (Moyer, 1996; Stahlberg, Sczensny, \& Braun, 2001). Female and male children and adults almost always attribute maleness to ostensibly genderless soft toys, even when their conversation partners refer to the toy as 'she' (Lambdin et al., 2003). Thus, in the absence of specific information about their gender social categories appear to be implicitly represented as male far more often than they are implicitly represented as female.

Such androcentic thinking is supported by the use of masculine generic pronouns to refer to individuals and groups. 'He' and 'she' are not equivalent terms in the English language. ' 'He' is the eleventh most commonly used English word, but 'she' is only the forty-sixth most commonly used word (Bragg, 2003; p. p.7). One reason that 'he' is more commonly used is that it also functions as a generic term to refer to persons of unknown gender. While the generic 'he' is sometimes described as a 'natural' use of English, its usage is the result of deliberate reforms by proscriptive grammarians in past centuries who presumed the superiority of males (Bodine, 1975). Although it would be unthinkable to conflate humanity with Whiteness in the way that it is routinely conflated with maleness (Hofstadter, 1985), such androcentric language is not recognized as sexist by all (Swim, Mallett, \& Stangor, 2004). Men are less likely to find such androcentric language sexist, particularly those who are more sexist themselves (Parks \& Robertson, 2004). Yet androcentric pronouns have implications for the ways that we think about women and men. Children give lower estimates for a female worker's performance when workers are described as 'he' rather than 'they,' 'he or she,' or 'she' (Hyde, 1984). Even among those adults who understand that 'he' has a generic meaning, the pronoun prompts mental imagery of males more than females (e.g., Gastil, 1990; Hamilton, 1988, 1991; $\mathrm{Ng}, 1990)$.

According to Bem (1993), the tendency to take men as the default gender leads to a second bias; the attribution of gender differences to women's nature more than to men's nature. This may occur because of a more general tendency to attribute inter-group differences to those groups who are not considered to be the default for the larger social category. Indeed, not only are gender differences attributed to women more than to men (Miller, Taylor \& Buck, 1991), but sexual orientation differences are attributed to lesbians and gay men more than to heterosexuals (Hegarty \& Pratto, 2001, 2004), and race differences are attributed to Blacks more than to Whites (Pratto, Hegarty, \& Korchmaros, in press; see also Devos \& Banaji, 2005). Such biases evidence the effects of exemplar-based mental representations called category norms (Kahneman \& Miller, 1986) which are constructed on-line, most often from prototypical exemplars of the category. Category norms make implicit the distinctive attributes of included exemplars, and render salient the distinctive attributes of excluded exemplars (see also Pratto, Korchmaros, \& Hegarty, in press). As the theory predicts, within social categories for which lower power groups are more typical, explanations of inter-group differences do not take those groups as 'the effect to be explained.' Rather, gender differences among elementary school teachers are understood to be about men as much as they are about women (Miller et al., 1991, Experiment 3), and sexual orientation differences among men 
living with HIV/AIDS are understood to be about straight men as much as they are about gay men (Hegarty \& Pratto, 2001, Experiment 2).

\section{Androcentric Thinking in Science}

These findings about the androcentric thinking of 'just plain folks' (Lave, 1988) raise the question of whether psychologists similarly take males as the default when constructing the meaning of gender differences that emerge in their research. Because psychology is a science, it might be assumed to be immune to the influence of such cultural biases as androcentrism. However, both Kuhn's (1970) notion of the 'paradigm' and Foucault's (1994) notion of the 'episteme' suggest that knowledge within the sciences depends on webs of historically particular implicit assumptions. Popper (1959, p. 37) demarcated science from other forms of knowledge on the basis of its fasfiability, but specified that the falsifiability of a theory was determined by social agreement within any given scientific community. ${ }^{2}$ In other words, despite their differences, the major philosophers of science of the twentieth century allow for systems of scientific thought to contain implicit assumptions that originate in scientists' shared cultural understandings rather than the normative procedures of scientific inference and deduction. Where the broader culture influences a scientific community, the interpretive practices of scientists and non-scientists are likely to be similar. The present research examines whether psychologists, like the participants in the experiments described above, implicitly assume that empirical gender differences show how women differ from men more than they show how men differ from women.

Our research examined psychological writing over the period 1965-2004. During this forty year period, feminist ideas became institutionalized in psychology (see Tiefer, 1991), and three effects of feminism's influence on psychology are particularly relevant to the current research. First, males ceased to be chronically overrepresented as authors of, and participants in, research studies (Gannon et al., 1991). Second, feminist psychology publications such as Psychology of Women Quarterly, Sex Roles and Feminism \& Psychology were founded which emphasized feminist values. Third, research psychologists acknowledged that they were vulnerable to androcentric biases and took steps to mitigate them. The American Psychological Association explicitly prohibited use of the generic 'he,' on the grounds that it was androcentric (e.g., APA Publication Manual Task Force, 1977), and research published since that time has complied with this directive (Gannon et al., 1992).

While these changes in psychologists' criteria of merit for research on gender were historic, we hypothesized that they had not completely eradicated androcentrism in psychology, and for three reasons. First, qualitative reviews have suggested that feminist research in psychology has tended to undo negative evaluations of women in traditional theories more often than undo the position of males as the standard of comparison within those theories (e.g., Crawford and Marecek, 1989; Mednick, 1989; Walsh, 1989). Second, the move to forbid the use of the generic 'he' met with considerable resistance (see Martyna, 1980 for a review and Hofstadter, 1985 for a satirical view of this debate). Androcentric practices may die hard among scientists because they are habitual for many of us, and are not recognized as being biases by all of us. Third, debates about the generic 'he' failed to address the androcentric tendency to explain differences as being about women rather than about men. Hegarty and Pratto (2001) showed that at least one team of scientific authors positioned heterosexuals and White people as 'the norm' and 
gay/lesbian and Black people as 'the effects to be explained' in spite of their awareness that so doing constituted a form of bias. Psychologists may be vulnerable to androcentric biases in their explanatory practices even if they recognize that such biases exist and consider them to be problematic. Successful attempts to extinguish the generic 'he' from academic writing do not necessarily disrupt androcentric thoughts (Prentice, 1994).

Thus, we predicted that while the use of the generic 'he' would no longer be visible in the psychological literature, an androcentric tendency to explain gender difference findings as being about women rather than men would still be evident. Our study included a third measure of androcentrism; we examined visuospatial constructions of gender differences. In science, males can be visually presented as the norm for humanity, as in successive editions of Grays Anatomy where most of the 'human' bodies have been transparently male (Petersen, 1998). We examined representations of gender differences in tables and graphs for evidence of androcentrism. Such visuospatial displays regularly accompany scientific text and serve to clarify its meaning (Shah \& Hoeffner, 2002). However, the information in visuospatial displays is encoded sequentially, and English language speakers encode spatial information from top to bottom (Clark \& Chase, 1972) and from left to right (Chatterjee, 2001; Maass \& Russo, 2003; Spalek \& Hammad, 2005; Tversky, Kugelman, \& Winter, 1991). We predicted that androcentrism would be evidenced by visuospatial displays that positioned data about men to the left of, or above, data about women. Displays that positioned data about men underneath, or to the right of, data about women were defined as gynocentric.

Finally, as our work was informed by norm theory (Kahneman \& Miller, 1986), we assumed that androcentric biases were not consequences of negative beliefs about women, but rather resulted from shared cognitive structures that positioned men as more typical members of the category 'human' than were women. Within categories where women are more typical, such effects were predicted to be absent or reversed. Psychologists have long taken mothers to be the preferred participants in research on parenting (Burman, 1994; Gannon, 1998). Accordingly, we predicted that androcentric biases would be absent or reversed when psychologists reported gender differences among parents.

\section{Method}

We systematically sampled articles over the period from 1965 to 2004 from four APA journals; Journal of Personality and Social Psychology (JPSP), Developmental Psychology (DP), Journal of Abnormal Psychology (JAP), and Psychology of Women Quarterly (PWQ). PWQ began publication in 1976, but it was included to assess whether androcentrism characterized feminist research as well as 'mainstream' nonfeminist research on gender differences. One issue per year of publication of each journal was selected at random. Every article within that issue that reported original empirical data was included in the corpus. Review articles, commentaries, and metaanalyses were excluded. This sampling procedure produced a corpus of 1859 articles. We recorded each article's year and journal of publication. Where the information was available, we also recorded the first author's gender, the proportion of male and female authors, and the proportion of male and female participants in the reported empirical studies. 
Twenty-one percent of the articles reported one or more empirical gender difference $(\mathrm{N}=388)$. We categorized this smaller set of articles into three groups according to the salience accorded to the gender differences reported. High salience articles mentioned gender differences in their titles, medium salience articles mentioned gender differences in their abstracts but not in their titles, and low salience articles did not mention gender differences in either their titles or abstracts. Several articles in $D P$ included both parents and children as study participants. For such articles, we treated children as the principal participants of these studies and reports of gender differences among parents were analyzed separately. This allowed a test of whether gender differences were reported similarly between 'females and males' and 'fathers and mothers'.

We examined the 388 articles for evidence of three types of androcentrism. First, we coded each article for the use of the generic 'he' anywhere in its text. Second, we examined descriptions and explanations of the observed gender differences within the 'results' and 'discussion' section, or sections, of each article. Following Miller et al. (1991), we counted all references to attributes of males and to attributes of females. We defined androcentrism as the tendency to describe and explain gender differences with reference to women's attributes. Each sentence clause that took a gender group as its subject was counted as a reference to that gender. For example, "Boys were significantly more overtly aggressive than girls" was coded as a reference to males (see Crick, Casas, \& Mosher, 1997; p.583). Finally, we counted the number of visuospatial displays of gender differences that presented data about each gender first. The second author completed all coding.

\section{Results}

\section{Representation of Male and Female Authors and Participants}

We first examined the inclusion of female and male authors and study participants in the articles we sampled. A 4 x 4 between-subjects ANOVA was conducted with decade of publication (1965-1974 vs. 1975-1984 vs. 1985-1994 vs. 1995-2004) and journal (JPSP vs. DP vs. JAP vs. $P W Q$ ) as independent variables, and the first author's gender as the dependent variables. We dummy coded female authors as ' 1 ' and male authors as ' 0 ' such that higher numbers referred to a greater representation of female authors. ${ }^{3}$ Significant main effects of decade of publication, $F(3,1822)=22.94, p<.001$, $\eta^{2}=.04$, journal of publication, $F(3,1822)=105.16, p<.001, \eta^{2}=.15$, and an interaction, $F$ $(8,1822)=3.57, p<.001, \eta^{2}=.02$, were observed. While male authors were initially vastly overrepresented, more equal representation emerged with time. Gender representation changed most markedly between the first two decades of the study for two reasons; female authors became better represented within DP, JAP, and JPSP, and $P W Q$ began publication in the second decade under study. Male authors were consistently underrepresented in $P W Q$ (see Table 1). ${ }^{4}$

Next we examined the inclusion of female and male study participants. A similar 4 x 4 ANOVA was conducted using the proportion of male participants in the reported studies as the dependent variable. Significant main effects of decade, $F(3,1441)=$ $24.41, p<.001, \eta^{2}=.05$, and journal, $F(3,1441)=56.02, p<.001, \eta^{2}=.10$, and an 
interaction, $F(8,1441)=3.60, p<.001, \eta^{2}=.02$, were observed. Male participants were overrepresented in earlier studies, but underrepresented in later studies. This occurred both because studies reported in JPSP and JAP came to include fewer male participants over time, and because female participants were consistently overrepresented in studies reported in $P W Q$ (see Table 2). Thus within the larger corpus of articles there was consistent evidence that psychological research ceased to over-represent males, both as study participants and as study authors over the last forty years. This pattern is consistent with past reviews of this literature (see Gannon et al., 1992). To examine androcentrism we next turned to the smaller corpus of 388 articles that reported gender differences.

Table 1: Proportion of Female First Authors by Publication and Decade (Sample Size in Parentheses).

\begin{tabular}{llllll}
\hline Journal & $1965-1974$ & $1975-1984$ & $1985-1994$ & $1995-2004$ & Total \\
\hline JPSP & $.15^{\mathrm{a}}(140)$ & $.24^{\mathrm{a}}(141)$ & $.26^{\mathrm{a}}(163)$ & $.26^{\mathrm{a}}(141)$ & $.23(585)$ \\
JAP & $.12^{\mathrm{a}}(121)$ & $.28^{\mathrm{b}}(92)$ & $.34^{\mathrm{b}}(147)$ & $.30^{\mathrm{b}}(130)$ & $.27(490)$ \\
DP & $.30^{\mathrm{a}}(107)$ & $.50^{\mathrm{b}}(129)$ & $.53^{\mathrm{b}}(166)$ & $.75^{\mathrm{c}}(150)$ & $.54(552)$ \\
PWQ & & $.78^{\mathrm{a}}(63)$ & $.83^{\mathrm{a}}(75)$ & $.86^{\mathrm{a}}(72)$ & $.82(210)$ \\
All Journals & $.18(368)$ & $.41(425)$ & $.48(551)$ & $.51(493)$ & $.49(1837)$ \\
\hline
\end{tabular}

Note: Twenty-two articles were excluded because the first authors' gender was ambiguous. Means within each row which do not share a superscript differ significantly (Tukey's HSD, $\alpha=$ $.05)$.

\section{Androcentric Pronoun Use}

Androcentric pronoun use was rare within the articles reporting gender differences. Only thirty of the 388 articles (i.e., 7.7\%) used the generic 'he.' Articles that used the generic 'he' were dummy coded as ' 1 ' and those that did not were dummy coded as ' 0 '. A $4 \times 4 \times 3 \times 2$ ANOVA with decade, publication, salience of gender differences (high vs. medium vs. low), and first author's gender as independent variables revealed only an effect of decade on androcentric pronoun use, $F(3,355)=21.83, p$ $<.001, \eta^{2}=.16$. Post hoc tests revealed that a greater proportion of articles used the generic 'he' during the first decade than the second decade $(M \mathrm{~s}=.28, .10$ respectively). No articles published after 1985 used the generic 'he'. Two articles each contained one use each of 'she' as a generic pronoun. Psychologists no longer use androcentric pronouns in their research publications (c.f., APA Publication Manual Task Force, 1977; Gannon et al., 1992).

\section{Verbal Descriptions and Explanations of Gender Differences}

Next we examined if empirical gender differences were described and explained as being about women or about men. A 4x4x3 $2 \times 2$ ANOVA was conducted with decade, journal, salience of gender differences, and first author's gender as withinsubjects factors, and the gender group referenced (females vs. males) as a within-subjects 
factor. Females' attributes were referenced more often than males' attributes, $F(1,300)=$ 11.43, $p=.001, \eta^{2}=.04(M \mathrm{~s}=9.57,7.23$ respectively), evidencing androcentrism. A significant main effect of the salience of gender differences was also observed. Females' and males' attributes were referenced most often in articles that made gender differences highly salient $(M=27.73)$, significantly less in medium salience articles $(M=21.46)$, and significantly less again in low salience articles $(M=9.25)$. No other main effects were significant. Female and male psychologists writing across the decades in different journals all rendered men and boys the norm for comparison, and women and girls 'the effect to be explained,' to much the same degree.

Table 2: Proportion of Male Study Participants by Publication and Decade (Sample Size in Parentheses).

\begin{tabular}{|c|c|c|c|c|c|}
\hline Decade & $1965-1974$ & $1975-1984$ & 1985-1994 & $1995-2004$ & Total \\
\hline JPSP & $.64^{\mathrm{a}}(100)$ & $.47^{\mathrm{b}}(111)$ & $.44^{\mathrm{b}}(104)$ & $.41^{\mathrm{b}}(101)$ & $.49(416)$ \\
\hline JAP & $.68^{\mathrm{a}}(86)$ & $.57^{\mathrm{b}}(76)$ & $.49^{b}(132)$ & $.49^{b}(121)$ & $.54(415)$ \\
\hline DP & $.53^{\mathrm{a}}(95)$ & $.50^{\mathrm{a}}(107)$ & $.51^{\mathrm{a}}(109)$ & $.51^{\mathrm{a}}(114)$ & $.51(425)$ \\
\hline PWQ & - & $.31^{\mathrm{a}}(58)$ & $.24^{\mathrm{ab}}(70)$ & $.16^{\mathrm{b}}(72)$ & $.23(200)$ \\
\hline Total & $.62(281)$ & $.48(352)$ & $(415)$ & $.41(408)$ & $.47(1456)$ \\
\hline
\end{tabular}

Note: Four hundred and three articles were excluded as the proportion of male and female participants was ambiguous. Means within each row which do not share a superscript differ significantly (Tukey's HSD, $\alpha=.05$ ).

A marginally significant interaction between the gender group referenced and the salience accorded to gender differences was also observed, $F(2,300)=2.93, p<.06, \eta^{2}=$ .02. Post hoc tests showed that there were equal numbers of references to females and males in low salience articles. However, in medium and high salience articles, there were significantly more references to females that to males. In other words, among the articles that reported gender differences, only those that mentioned those differences in their abstracts or titles contained large numbers of references to the attributes of gender groups and particularly to attributes of women and girls (see Figure 1).

\section{Visuospatial Displays of Gender Differences}

Finally, we examined visuospatial displays of gender differences. Two hundred and eighty-two of the 388 articles that reported gender differences (i.e., 72.7\%) included at least one table or graph that visually represented gender differences. On average, each of these 282 articles included 2.35 such visuospatial displays. We calculated the proportion of androcentric and gynocentric visuospatial displays within each article. A far greater proportion of these were androcentric than were gynocentric $(M \mathrm{~s}=.74, .26), t$ $(281)=29.87, p<.001$. Again this androcentric pattern was quite consistent across the

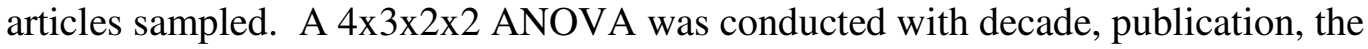
salience of gender differences, and first author's gender as within-subjects factors, and the proportion of androcentric visuospatial displays as the dependent variable. Only a 
main effect of publication was observed, $F(3,203)=5.13, p<.01, \eta^{2}=.07$. Post hoc tests showed that articles in $P W Q$ and JPSP had fewer androcentric visuospatial displays $(M=.63, .68$ respectively) than articles in $D P(M=.87)$. Proportions of androcentric visuospatial displays in JAP articles did not differ significantly from the means for other journals $(M \mathrm{~s}=.72)$. However, a significant majority of visuospatial displays within the articles sampled from each of the four journals were androcentric, all $t>2.14$, all $p<.005$.

Figure 1: Mean Number of References to Females and Males by Salience of Gender Differences in Articles' Text

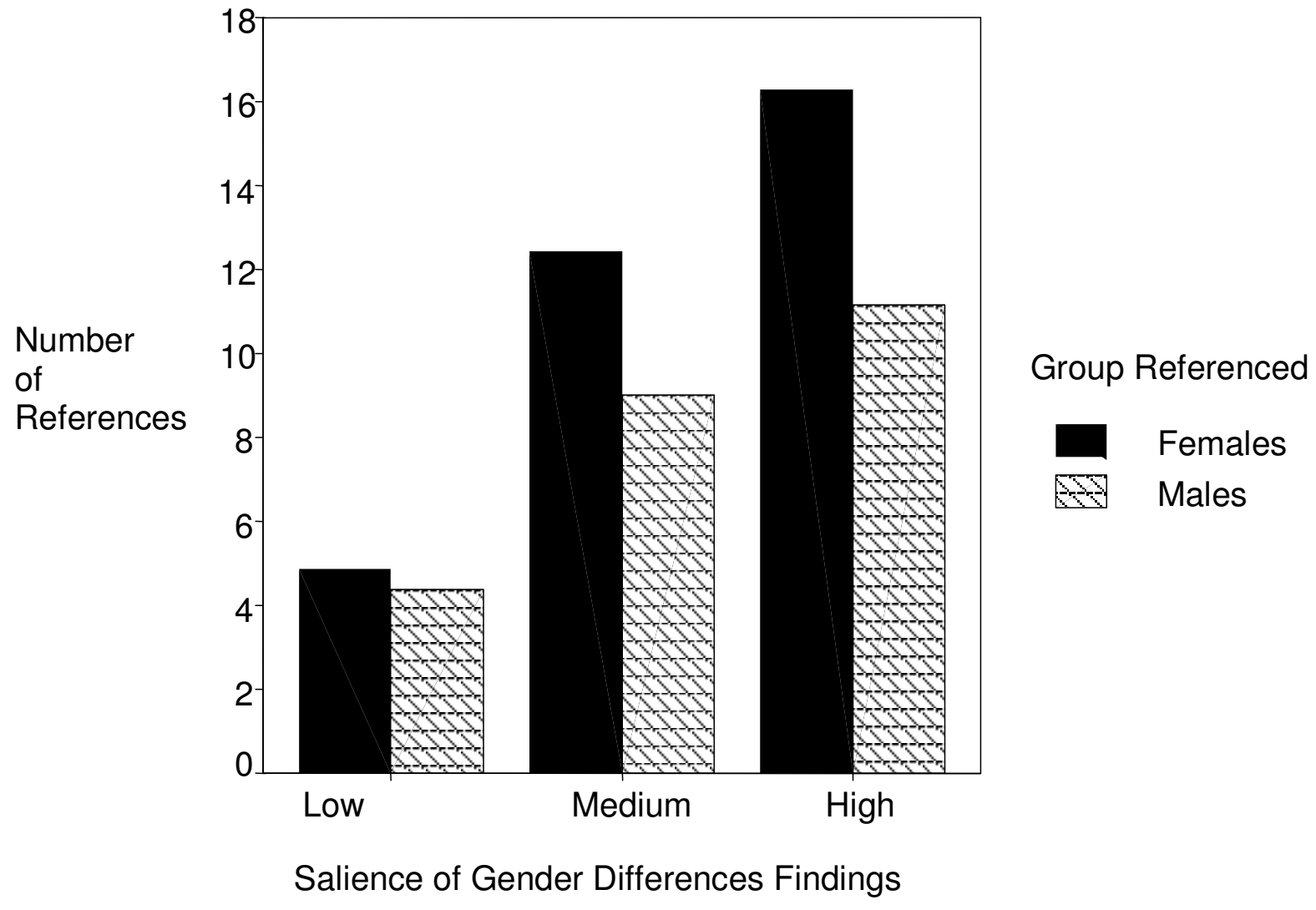




\section{Gender Differences Among Parents}

Within the entire corpus, only twenty articles reported gender differences between mothers and fathers. The text of these articles' 'results' and 'discussion' sections were coded as before. These contained an equal number of references to mothers and fathers, $t$ $<1,(M \mathrm{~s}=11.55,11.30)$. Each article contained an average of 1.85 visuospatial displays of gender differences between parents. In contrast to the displays in the main corpus, many more of these visuospatial displays were gynocentric than were androcentric $(M \mathrm{~s}=$ $.81, .19), t(17)=3.48, p<.01$. Thus, verbal androcentrism was not evidenced but visuospatial gynocentrism was evidenced in the construction of psychological gender differences among parents.

\section{Discussion}

This content analysis shows both stability and change in the effects of androcentrism on psychologists' constructions of gender differences. More participants in, and authors of, psychological studies are female than in previous decades, and research psychologists have long since extinguished the generic 'he' from their vocabulary. Yet, other androcentric biases remain; explanations of gender differences focus on women more than on men and visuospatial displays position men first and women second. Explanations of gender differences among parents focus equally on mothers and fathers, and visuospatial displays of such differences position mothers first and fathers second.

Were the articles that we sampled representative of the psychological literature in general? Our corpus included articles from four APA publications that publish high quality research, and we deliberately focused on these journals to yield a large number of articles that reported gender differences. To assess the representativeness of these findings, we examined a broader range of journals in less depth. We used the database Psychinfo to search for articles published between 1965 and 2004 that positioned one gender group (e.g., women) as the background comparison for the other gender group (e.g., men) with the phrases 'less than' and 'more than'. For example, we searched for articles whose abstracts contained both the phrase 'less than women' and the word 'men' and those that contained both the phrase 'less than men' and the word 'women.' As Table 3 shows, psychologists' abstracts have been more likely to position females as 'more than' or 'less than' males, than they are to position males as 'more than' or 'less than' females. Furthermore, this asymmetry is not observed with regard to gender differences among parents. Note also that 'more than' constructions were vastly preferred over 'less than' constructions of differences (Clark, 1969; see also Hegarty \& Pratto, 2001). Thus, androcentric constructions of gender differences appear to be the norm beyond the four journals that we examined in depth; males are taken as the reference point for gender difference comparisons, except where women are the more typical group. These findings prompt questions about psychologists' individual cognitive processes and the 'social construction' of knowledge among scientists.

\section{Cognitive Explanations}

These findings suggest that psychologists behave very much like other kinds of people in at least three ways. First, whether women and men happen to be research 
psychologists or experimental participants, they focus typically explanations of gender differences on females, except where females are more typical of the overarching category (e.g., Miller et al., 1991). However, psychologists' explanations are less asymmetric than are experimental participants's explanations; participants typically produce almost three times as many references to atypical groups as to typical groups (see Pratto, Hegarty \& Korchmaros, in press). Less extreme bias was observed here.

Second, psychologists' visuospatial representations of gender differences overwhelmingly positioned men first, except where parents were being depicted. Again, psychologists and experimental participants appear to be similar. In a recent experiment, we found undergraduates to prefer to graph relations between typical and atypical members of natural and social categories by positioning the more typical entity first (Hegarty \& Ungar, 2006). In our experiment, as in the research reported here, data about males were displayed before data about females about $75 \%$ of the time. It is known that real world knowledge affects the interpretation and recall of the information in graphs (see Shah \& Hoeffner, 2002 for a review), and that graph format can subtly cue information about the relationships being displayed (Shah, Mayer, \& Hegarty, 1999; Zachs \& Tversky, 1999). Future research should examine whether people expect graphs to depict more typical entities first, and whether the tendency to display gender differences in this way generalizes to other social cateogries.

Third, the lack of any moderation of these findings by the year of the published study suggests that androcentric representations of gender differences have not been affected by the explicit proscription against the generic 'he.' Again, psychologists appear akin to other people; extinguishing the use of 'he' does not undo other forms of androcentric thinking (Prentice, 1994).

Social Constructionist Explanations

While cognitive explanations of these findings are necessary, they may be incomplete if they overlook the social processes through which knowledge about social categories is constructed in interaction (c.f., Antaki, 1981; Crawford, 1995; Edwards \& Potter, 1993; Potter \& Wetherell, 1987). Social constructionist and cognitive explanations of persistent behaviour patterns are not mutually incompatible; both perspectives emphasize that people are constructive meaning-makers, and neither perspective necessarily assumes that scientific meaning making is beyond cultural influence (Jost \& Kruglanski, 2002). Social constructionism directs attention towards the ways that the rhetorical demands of situations affect the kinds of discourse that is produced (Billig, 1987). When scientists submit papers for publication, there is a rhetorical demand to show that new findings are being demonstrated. Thus, in a field where male participants have been the norm, data about females may be 'new' and data about males may be 'given' information (Clark \& Haviland, 1977). Indeed, when people generalize from one group to another, they often take their own guesses about the second group as 'the effect to be explained' (Hegarty \& Chrysochoou, 2005).

However, our results show that women and girls have been represented as study participants for some time. Consequently, some process other than statistical underrepresentation appears to maintain androcentrism in psychology. It is possible that androcentric psychological theories may play a role (Bem, 1993). In addition to explaining atypical groups, people tend to focus explanations on atypical events (Kahneman \& Miller, 1986; Kanazawa, 1992), and models which conflate men with the 
norm will continually position women's and girls' behaviour as surprising. Freud (1925, p. 249) admitted that psychoanalysts 'have been in the habit of taking as the subject of our investigations the male child' prior to explaining gender differences in terms of penis envy. Models of human evolution often presume that men's activities, such as hunting and warfare, to have spurred on the development of the species (Fedigan, 1986). Androcentrism in cognitive psychology appears less obvious. However, Oyama (2000) notes that the cognitive metaphor of 'mental programming' presumes a humulculus programmer who programmes the mind, and we are likely to call to mind a male, rather than a female, programmer to instantiate our understanding of this metaphor. Such theoretical choices as these are only partially determined by data, and they may reflect and support androcentric thinking in psychology by positioning men's and boy's behaviour as ordinary, and girls' and women's behaviour as exceptional and noteworthy. Does Androcentrism Matter?

Taken on their own, our findings demonstrate that androcentric constructions of gender differences are prevalent, but not that they are harmful. However, gender difference research can reify stereotypes, particularly when attributed to biological factors (Brescoll and LaFrance, 2004, see also Hegarty \& Pratto, 2001, 2004; Hoffman \& Hurst, 1990; Martin \& Parker, 1995). Claims about empirical gender differences can also create stereotype threat effects, and produce the very gender differences they describe (Spencer, Steele, \& Quinn, 1999; Steele, 1997). Where androcentrism is systematic, as in psychology, reports of 'gender differences' are not simply about 'gender'; they are systematically about women and girls more than they are about men and boys. As a result, it is not 'gender stereotypes' but stereotypes of women and girls that we risk reifying when we report empirical differences. Thus, psychologists may contribute to the degree to which 'women have gender, and blacks have race more than men and whites respectively do' (Fiske, 1998, p. 366).

Explanation is a constructive process (Asch \& Zukier, 1986; Kunda, Miller, \& Claire, 1990), and people can come to belief their own explanations of social science data, even if the relevant data have been debunked (Anderson \& Sechler, 1986). As a result of focusing explanations on atypical groups such as women, lesbians and gay men, ethnic minorities and others, people of all identities may form more rigid stereotypes about such groups. Indeed, people do tend to hold more essentialist beliefs about low status groups than about high status groups (Haslam, Rothchild, \& Ernst, 2000).

When it goes without saying that boys and men are the default groups against which girls and women are to be compared, male privilege may also be reified. Norms are communicated more by what goes unspoken and taken for granted in discourse, rather than that which is explicitly stated (Miller \& Prentice, 1996). This appears to be the case in regard to who becomes the 'normative' participant in psychological research also. Historically, as experimental psychology research increasingly focused on undergraduates, participants' identities as undergraduates became mentioned less often in research articles, while other participants' identities continued to be designated (Danziger, 1990). Scholarship on the privilege enjoyed by Whites (e.g., Devos \& Banaji, 2005; Dyer, 1997; Fine, Weis, Powell, \& Wong, 1997; Leach, Snider, \& Iyer, 2002; Macintosh, 1998; Powell, Branscombe, \& Schmitt, 2005), men (Bem, 1993; De Beauvoir, 1949 Edley \& Wetherell, 1995), English-language speakers (Hill, 1999) and heterosexuals (Bricknell, 2000; Hegarty, Pratto, \& Lemieux, 2004; Sedgwick, 1990) all 
call attention to the low salience of group identity as a critical component of the phenomenology of privilege. Psychologists' unintentional androcentrism may contribute to the perpetuation of male privilege.

Concluding Thoughts

We will conclude with some thoughts on how our research reframes 'metatheoretical' debates about the psychology of gender (see Willig, 1991). The androcentric practices described here provide a new vantage point from which to view debates about the science and politics of comparing women and men. In the past, psychologists have been enjoined to avoid exaggerating gender differences (Baumeister, 1988; Favreau, 1997; McHugh, Koeske, \& Frieze, 1986; Hare-Mustin \& Marecek, 1990), to report similarities and small differences (Rothblum, 1988), to report empirical differences as accurately as possible (Eagly, 1995), and to trust in the value neutrality of a 'free marketplace of ideas' (Scarr, 1988).

As often happens in psychology, all sides in this debate express important truths (see McGuire, 1973). We agree with Eagly (1995) and Scarr (1988) that psychologists have a responsibility to report gender similarities and differences as accurately as possible. To do otherwise would misrepresent our best knowledge about gender, and reduce public confidence in psychological science. However, our research is consistent with postmodernist arguments that psychology can be characterized by both 'beta bias,' by which women are ignored, and 'alpha bias,' by which gender differences are exaggerated (Hare-Mustin \& Marecek, 1990). Empirical observation of gender differences can be described and explained in myriad ways, and cultural biases - such as androcentrism - can determine which kinds of constructions of gender differences are transacted within scientific communities.

\section{Notes}

1. Third person pronouns afford androcentrism differently in different languages. In contrast to English, Romance languages (such as Romanian, French, Spanish) specify gender in both the plural and singular third person pronoun. For mixedsex groups, the third person plural masculine pronoun is used in all romance languages. In contrast, Finno-Ungric languages (such as Turkish, Finnish, and Hungarian) do not specify gender in either the singular or plural third person pronoun.

2. As my interpretation of Popper's work goes against the grain of much social and cognitive psychology which uses Popper's criterion of falsification as a normative standard against which the constructive activities of participants are judged (e.g., Wason, 1960; Snyder \& Swann, 1978), it is well to remember how specific Popper $(1959$, p. 37) was on this point. "My criterion of demarcation will accordingly have to be regarded as a proposal for an agreement or convention. As to the suitability of any such convention opinions may differ; and a reasonable discussion of these questions is only possible between parties having some purpose in common. The choice of that purpose must, of course, be ultimately a matter of decision, going beyond rational argument (emphasis in original).

3. All post-hoc tests in the paper are Tukey's HSD $(\alpha=.05)$. 
4. To check that these conclusions were not biased by focusing on the gender of first authors rather than on all study authors, we calculated the proportion of female and male authors of each article and repeated the analysis. Similar conclusions were reached. The proportions of authors of each article who were female increased across the four decades of the study $(M \mathrm{~s}=.19, .43, .45, .49$ respectively) and varied across the four journals $(M \mathrm{~s}=.27$ for both JPSP and $J A P, .53$ for $D P$ and .77 for $P W Q$ ).

\section{Author Note}

Acknowledgment: We thank Jean Portman for library assistance, and James Cutting, Alice Eagly, and Mary Hegarty for comments on earlier drafts of this manuscript. Correspondence should be addressed to Peter Hegarty, SPERI, Department of Psychology, University of Surrey, Guildford, GU2 7XH, United Kingdom, p.hegarty@surrey.ac.uk, +44 (0) 1483686898.

\section{References}

APA Publication Manual Task Force (1977). Guidelines for non-sexist language in APA journals: Publication Manual change sheet 2. American Psychologist, 32, 498-494.

Anderson, C.A., \& Sechler, E.S. (1986). Effects of explanation and counterexplanation on the development and use of social theories. Journal of Personality and Social Psychology, 50, 24-34.

Antaki, C. (Ed.). (1981). The psychology of ordinary explanations of social behaviour. London: Academic Press.

Asch, S.E. \& Zukier, H. (1984). Thinking about persons. Journal of Personality and Social Psychology, 46, 1230-1240.

Augustinos, M., \& Walker, I. (1995). Social cognition: An integrated introduction. London: Sage.

Baumeister, R. F. (1988). Should we stop studying sex differences altogether? American Psychologist, 43, 1092-1095.

Bem, S. (1993). The lenses of gender: Transforming the debate on sexual inequality. New Haven, CT: Yale University Press.

Billig, M. (1987). Arguing and thinking: A rhetorical approach to social psychology. Cambridge: Cambridge University Press.

Black, K.N. \& Stevenson, M.R. (1984). The relationship of self-reported sex-role characteristics and attitudes toward homosexuality. Journal of Homosexuality, $10,83-93$.

Bodine, A. (1975). Androcentrism in prescriptive grammar. Language in Society, 4, $129-146$.

Bragg, M. (2003). The adventure of English: The biography of a language. London: Hodder and Stoughton

Bricknell, C. (2000). Heroes and invaders: Gay and lesbian pride parades and the public/private distinction in New Zealand media accounts. Gender, Place, and Culture, 7, 163-178. 
Brescoll, V. \& LaFrance, M. (2004). The correlates and consequences of newspaper reports of research on sex differences. Psychological Science, 15, 515-520.

Broverman, I.K., Broverman, D.M., Clarkson, F.E., Rosenkrantz, P.S., \& Vogel, S.R. (1970). Sex-role stereotypes and clinical judgments of mental health. Journal of Clinical and Consulting Psychology, 34, 1-7.

Burman, E. (1994). Deconstructing developmental psychology. London: Routledge.

Chatterjee, A. (2001). Language and space: Some interactions. Trends in Cognitive Science, 5, 55-61.

Clark, H.H. (1969). Linguistic processes in deductive reasoning. Psychological Review, 76, 387-404.

Clark, H.H., \& Chase, W.G. (1972). On the process of comparing sentences against pictures. Cognitive Psychology, 3, 472-517.

Clark, H. \& Haviland, S. (1977). Comprehension and the given-new contract. In R. Freedle (ed.), Discourse production and comprehension (pp. 1-40). Lawrence Erlbaum Associates, Hillsdale, N.J.,.

Crawford, M. (1995). Talking difference: On gender and language. London: Sage.

Crawford, M., \& Marecek, J. (1989). Psychology reconstructs the female: 1968-1988. Psychology of Women Quarterly, 13, 147-165.

Crick, N.R., Casas, J.F. \& Mosher, M. (1997). Relational and overt aggression in preschool. Developmental Psychology, 33, 579-588.

Danziger, K. (1990). Constructing the subject: Historical origins of psychological research. New York: Cambridge University Press.

DeBeauvoir, S. (1949/1972). The second sex. [Trans. H. M. Parshley] London: Penguin.

Devos, T., \& Banaji, M. (2005). American = White? Journal of Personality and Social Psychology, 88, 447-466.

Dyer, R. (1997). White. London: Routledge.

Eagly, A. H. (1995). The science and politics of comparing women and men. American Psychologist, 50, 145-158.

Eagly, A.H., \& Kite, M.E. (1987). Are stereotypes of nationalities applied to both women and men? Journal of Personality and Social Psychology, 53, 451-462.

Edley, N., \& Wetherell, M. (1995). Men in perspective: Practice, power and ideology. Hemel Hempstead: Prentice Hall.

Edwards, D., \& Potter, J. (1993). Language and causation: A discursive action model of description and attribution. Psychological Review, 100, 23-41.

Favreau, O.E. (1997). Sex and gender comparisons: Does null hypothesis testing create a false dichotomy? Feminism \& Psychology, 7, 63-81.

Fedigan, L.M. (1986). The changing role of women in models of human evolution. Annual Review of Anthropology, 15, 25-66.

Fine, M., Weis, L., Powell, L.C., \& Wong, L.M. (Eds.). (1997). Off White: readings on race, power, and society. New York: Routledge.

Fiske, S. T. (1998). Stereotyping, prejudice, and discrimination. In D. T. Gilbert, S. T. Fiske, \& G. Lindzey (Eds.), Handbook of Social Psychology (pp. 357-411). Boston: McGraw-Hill.

Foucault, M. (1970). The order of things. New York: Vintage.

Freud, S. (1925/1961). Some psychical consequences of the anatomical distinction between the sexes. In J. Stratchey (Ed.) The standard edition of the complete 
psychological works of Sigmund Freud: Volume xix, pp. 243-258. The Hogarth Press: London.

Gannon, L. (1998). The impact of medical and sexual politics on women's health. Feminism \& Psychology, 8, 285-302.

Gannon, L., Luchetta, T., Rhodes, K., Pardie, L., \& Segrist, D. (1992). Sex bias in psychological research: Progress or complacency? American Psychologist, 47, 389-396.

Gastil, J. (1990). Generic pronouns and sexist language: The oxymoronic character of masculine generics. Sex Roles, 23, 629-643.

Hamilton, M.C. (1988). Using masculine generics: Does generic He increase male bias in the user's imagery? Sex Roles, 19, 785-799.

Hamilton, M.C. (1991). Masculine bias in the attribution of personhood: People = male, male = people. Psychology of Women Quarterly, 15, 393-402.

Hare-Mustin, R.T., \& Marecek, J. (1990). Gender and the meaning of difference: Postmodernism and psychology. In R.T. Hare-Mustin \& J. Marecek (Eds.), Making a difference: Psychology and the construction of gender (pp. 22-64). New Haven, CT: Yale University Press.

Haslam, N. Rotschild, N. \& Ernst, D. (2000). Essentialist beliefs about social categories. British Journal of Social Psychology, 39, 113-127.

Hegarty, P. \& Chryssochoou, X. (2005). Why 'our' policies set the standard more than 'theirs': Category norms and generalization between European Union countries. Social Cognition, 23, 491-529.

Hegarty, P., \& Pratto, F. (2001). The effects of category norms and stereotypes on explanations of intergroup differences. Journal of Personality and Social Psychology, 80, 723-735.

Hegarty, P., \& Pratto, F. (2004). The differences that norms make: Empiricism, social constructionism and the interpretation of group differences. Sex Roles: A Journal of Research, 50, 445-453.

Hegarty, P., Pratto, F., \& Lemieux, A.F. (2004). Heterosexist ambivalence and heterocentric norms: Drinking in intergroup discomfort. Group Processes and Intergroup Relations, 7, 119-130.

Hegarty, P. \& Ungar, S. (2006). Preferences for order of information about gender in graphs. Unpublished data: University of Surrey.

Hill, J.H. (1999) Language, race, and White public space. American Anthropologist, 100, 680-689.

Hoffman, C. \& Hurst, N. (1990). Gender stereotypes: Perception or rationalization? Journal of Personality and Social Psychology, 58, 197-208.

Hofstadter, D.R. (1985). A person paper on purity in language. In Metamagical themes: Questing for the essence of mind and pattern (pp. 159-172). New York: Basic Books.

Hyde, J.S. (1984). Children's understanding of sexist language. Developmental Psychology, 20, 697-706.

Hyde, J.S. (2005). The gender similarities hypothesis. American Psychologist, 60, 581-592. 
Jost, J.T. \& Kruglanski, A.W. (2002). The estrangement of social constructionism and experimental social psychology: History of the rift and prospects for reconciliation. Personality and Social Psychology Review, 6, 168-187.

Kahneman, D. \& Miller, D.T. (1986). Norm theory: Comparing reality to its alternatives. Psychological Review, 93, 136-153.

Kanazawa, S. (1992). Outcome or expectancy? Antecedents of spontaneous causal attribution. Personality and Social Psychology Bulletin, 18, , 659-668.

Kitzinger, C. (Ed.). (1994). Should psychologists study sex differences? Feminism \& Psychology, 4, 501-546.

Kuhn, T. (1970). The structure of scientific revolutions, Second edition. Chicago: University of Chicago Press.

Kunda, Z., Miller, D.T., \& Claire, T. (1990). Combining social concepts: The role of causal reasoning. Cognitive Science, 14, 551-577.

Lambdin, J.R., Greer, K.M., Jibotian, K.S., Wood, K.R., \& Hamilton, M.C. (2003). The animal $=$ male hypothesis: Children's and adult's beliefs about the sex of non sex-specific stuffed animals. Sex Roles, 48, 471-482.

Lave, J. (1988). Cognition in practice: Mind, mathematics and culture in everyday life. Cambridge: Cambriduge University Press.

Leach, C.W., Snider, N., \& Iyer, A. (2002). "Poisoning the consciences of the fortunate": The experience of relative advantage and support for social equality. In I. Walker (Ed.), Relative deprivation: Specification, development and integration (pp. 136163). New York: Cambridge University Press.

Maass, A. \& Russo, A. (2003). Directional bias in the mental representiaton of spatial events: Nature or culture? Psychological Science, 14, 296-301.

Mahalingam, R. (2003). Essentialism, culture and beliefs about gender among the Aravanis of Tamil Nadu, India. Sex Roles, 49, 489-496.

Martin, C.L., \& Parker, S. (1995). Folk theories about sex and race differences. Personality and Social Psychology Bulletin, 21, 45-57.

Martyna, W. (1980). Beyond the he/man approach. Signs: Journal of Women in Culture and Society, 5, 482-493.

McGuire, W. (1973). The yin and yan of progress in social psychology. Journal of Personality and Social Psychology, 26, 446-456.

McHugh, M., Koeske, R.D., \& Frieze, I.N. (1986). Issues to consider in conducting non-sexist psychological research. American Psychologist, 41, 879-889.

McIntosh, P. (1998). White privilege: Unpacking the invisible knapsack. In M. McGoldrick (Ed.), Revisioning family therapy: Race, culture, and gender in clinical practices (pp. 147-152). New York: Guildford Press.

Mednick, M.T. (1989). On the politics of psychological constructs: Stop the bandwagon, I want to get off. American Psychologist, 44, 1118-1123.

Miller, D.T., \& Prentice, D.A. (1996). The construction of social norms and standards. In E.T. Higgins \& A. W. Kruglanski (Eds.), Social psychology: Handbook of basic principles (pp. 799-829). New York: Guildford.

Miller, D.T., Taylor, B., \& Buck, M.L. (1991). Gender gaps: who needs to be explained? Journal of Personality and Social Psychology, 61, 5-12.

Moyer, R. (1997). Covering gender on memory's front page: Men's prominence and women's prospects. Sex Roles, 37, 595-618. 
$\mathrm{Ng}$, S.H. (1990). Androcentric coding of man and his in memory by language users. Journal of Experimental Social Psychology, 26, 455-464.

Oyama, S. (2000). The ontogeny of information: Developmental systems and evolution. Duke University Press: Durham, NC.

Parks, J.B. \& Robertson, M.A. (2004). Attitudes toward women mediate the gender effect on attitudes toward sexist language. Psychology of Women Quarterly, 28, 233-239.

Petersen, A. (1998). Sexing the body: Representations of sex differences in Gray's Anatomy, 1858 to the present. Body \& Society, 4, 1-15.

Popper,K. (1959). The logic of scientific discovery. New York: Basic Books.

Potter, J. \& Wetherell, M. (1987). Discourse and social psychology: Beyond attitudes and behaviour. London: Sage.

Powell, A.A., Branscombe, N.R., \& Schmitt, M.T. (2005). Inequality as ingroup privilege or outgroup disadvantage: The impact of group focus on collective guilt and interracial attitudes. Personality and Social Psychology Bulletin, 31, 508 521.

Pratto, F., Hegarty, P. \& Korchmairos, J. (in press). Who gets stereotyped? How communication practices and category norms lead people to stereotype particular people and groups. To appear in Y. Kashima, K. Fiedler, \& P. Freytag (Eds.), Stereotype dynamics: Language-based approaches to stereotype formation, maintenance, and change. Mahwah, NJ: Lawrence Erlbaum Associates.

Pratto, F., Korchmaros, J. N., \& Hegarty, P. (in press). When race and gender go without saying. Social Cognition.

Prentice, D.A. (1994). Do language reforms change our way of thinking? Journal of Language and Social Psychology, 13, 3-19.

Rothblum, E. D. (1988). More on reporting sex differences. American Psychologist, 43, 1095.

Scarr, S. (1988). Race and gender as psychological variables: Social and ethical issues. American Psychologist, 43, 56-59.

Sedgwick, E.K. (1990). Epistemology of the closet. Berkeley, CA: University of California Press.

Shah, P., \& Hoeffner, J. (2002). Review of graph comprehension research: Implications for instruction. Educational Psychology Review, 14, 47-69.

Shah, P., Mayer, R., \& Hegarty, M. (1999). Graphs as aids to knowledge construction: Signaling techniques for guiding the process of graph comprehension. Journal of Educational Psychology, 91, 690-702.

Silveira, J. (1980). Generic masculine words and thinking. N C. Kramarae (Ed.), The voices and words of women and men (pp. 165-178). Oxford: Pergammon.

Snyder, M., \& Swann, W.B. (1978). Hypothesis-testing porcesses in social interaction. Journal of Personality and Social Psychology, 36, 1202-1212.

Spalek, T.M. \& Hammad, S. (2005). The left-to-right bias in inhibition of return is due to the direction of reading. Psychological Science, 16, 15-18.

Spencer, S.J., Steele, C.M., \& Quinn, D.M. (1999). Stereotype threat and women's math performance. Journal of Experimental Social Psychology, 35, 4-28. 
Stahlberg, D., Sczesny, S., \& Braun, F. (2001). Name your favourite musician: Effects of masculine generics and their alternatives in German. Journal of Language and Social Psychology, 20, 464-469.

Steele, C.M. (1997). A threat in the air: How stereotypes shape intellectual identity and performance. American Psychologist, 52, 613-629.

Stroessner, S. J. (1996). Social categorization by race or sex: Effects of perceived non-normalcy on response times. Social Cognition, 14, 247-276.

Swim, J.K., Mallett, R., \& Stangor, C. (2004). Understanding subtle sexism: Detection and use of sexist language. Sex Roles, 51, 117-128.

Tiefer, L. (1991). A brief history of the Association for Women in Psychology: 1969 1991. Psychology of Women Quarterly, 15, 635-649.

Tversky, B., Kugelman, S. \& Winter, A. (1991). Cross-cultural and developmental trends in graphic productions. Cognitive Psychology, 23, 515-557.

Walsh, R. (1989). Do research reports in mainstream feminist psychology journals reflect feminist values? Psychology of Women Quarterly, 13, 433-444.

Wason, P. C. (1960). On the failure to eliminate hypotheses in a conceptual task. Quarterly Journal of Experimental Psychology, 12, 129-140.

Willig, M.A. (1985). Metatheoretical dilemmas in the psychology of gender. American Psychologist, 40, 800-811.

Zachs, J., \& Tversky, B. (1999). Bars and lines: A study of graphic communication. Memory and Cognition, 27, 1073-1079.

Zárate, M., \& Smith, E.E. (1990). Person categorization and stereotyping. Social Cognition, 8, 161-185. 
Table 3. Number of Abstracts Containing 'More Than' and 'Less Than' Constructions of Gender Differences Using Each Gender Group as the Background of the Comparison.

\begin{tabular}{lllll}
\hline Comparative Phrase & "more than" & "less than" & Total (\%) & $\chi^{2}$ \\
\hline Background Term. & & & & \\
Wom?n & 3916 & 82 & $3998(65.5)$ & \\
M?n & 2083 & 24 & $2107(34.5)$ & $292.86 * * *$ \\
Female* & 5670 & 72 & $5732(56.2)$ & \\
Male* & 4416 & 44 & $4460(43.8)$ & $158.75^{* * *}$ \\
Boy* & 1833 & 37 & $1870(56.4)$ & \\
Girl* & 1429 & 19 & $1448(43.6)$ & $53.67 * * *$ \\
Mother* & 296 & 98 & $394(47.4)$ & \\
Father* & 430 & 8 & $438(52.6)$ & .96 n.s. \\
\hline
\end{tabular}

$* * * p<.001$, n.s. $=$ non-significant.

Note: For each pair of terms, Psychinfo was searched for abstracts including the relevant comparative phrase adjacent to the relevant background term (e.g., more adj than adj $w o m ? n)$ and the compliment of that term (e.g., $m ? n)$. On the Psychinfo data base, the operator "*" allows for any completion of the term. For example, a search for mother* will yield articles including such words as mother, mothers, and motherhood. The operator "?" will search for words that include any letter in that position. Thus, a search for wom? $n$ will yield articles including the words woman and women. The term adj limits the search to abstracts that include the words only when they are adjacent to each other. 
Figure 1: Mean Number of References to Females and Males by Salience of Gender Differences in Articles' Text

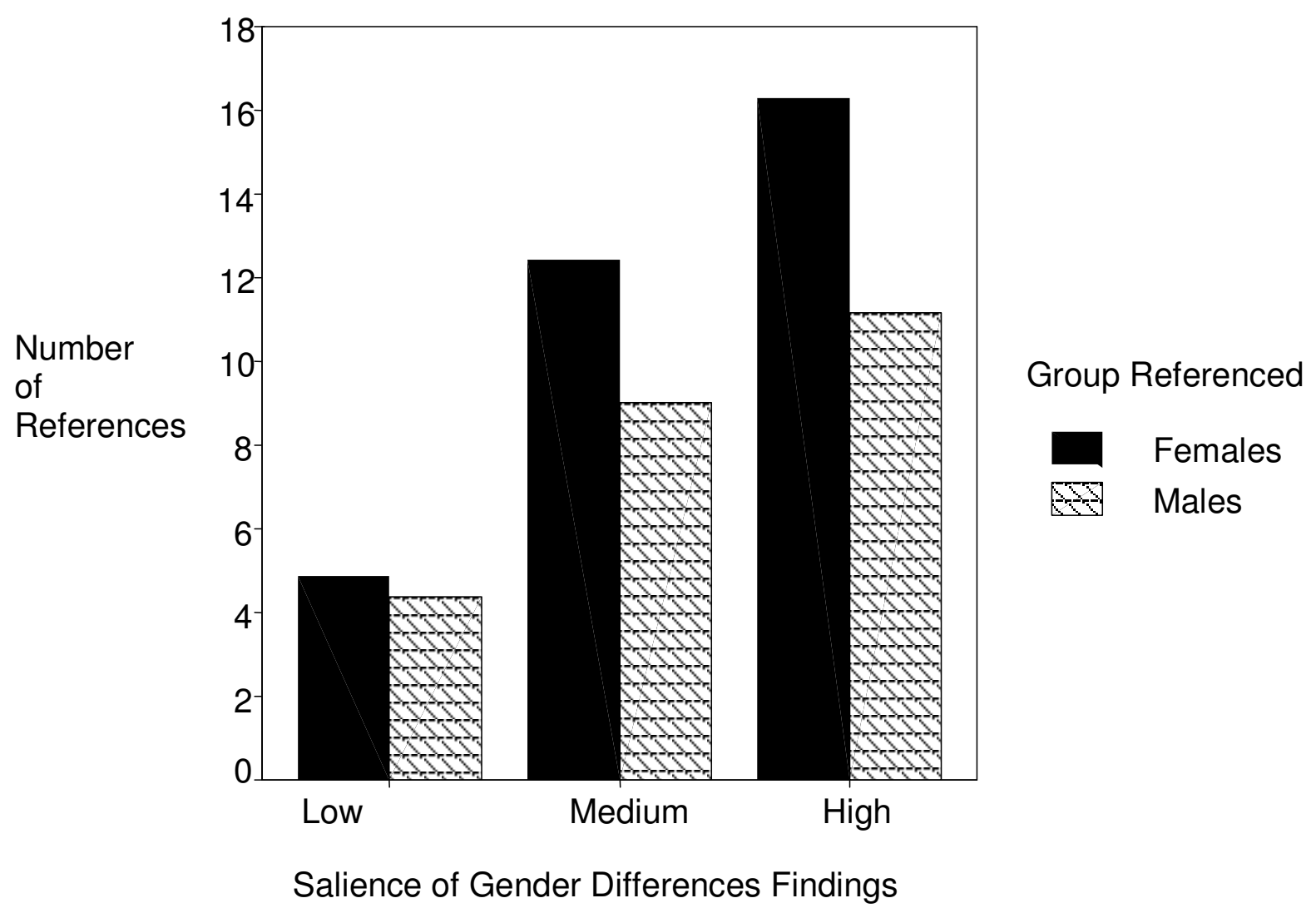

